\title{
Importance and Effectiveness of Training and Development
}

\author{
Ganesh M. \\ HR Coordinator, Human Resources, VIT University, Vellore, Taminadu, India \\ ganesh.m@vit.ac.in \\ Dr. R. Indradevi \\ Associate Professor, VIT Business School, VIT University, Vellore, Tamilnadu, India \\ Email: rindradevi@vit.ac.in
}

\section{Doi:10.5901/mjss.2015.v6n1p334}

\begin{abstract}
The paper intends to review the literature on Training \& development. It proposes to explore the importance \& effectiveness of Training \& development at a Private University. The paper proposes an empirical study on importance \& effectiveness of Training \& development through a survey on Deans/Sec Heads who in turn evaluate the Staffs at work. Training and development plays an important role in the effectiveness of organizations and to make experience people to do work effectively \& effectively. It is said that training has implications for productivity, commitment to the work and personal development. All corporate / companies must train people and develop their staff. Most of the organization are aware of this requirement and make invest and do many things for training and development. The training which we give to the staffs may be technical training or soft skills / behavioral training. It is also said making investment in training and development in companies in generally said to be as good management practice and to maintain appropriate expertise in the particular field and in future too. The objective of the research paper is to collect and analyze data regarding the importance and effectiveness of training. The research will enable us to identify the training importance \& effectiveness.
\end{abstract}

Keywords: Training, Importance, effectiveness

\section{Introduction}

Training is said to be the acquisition of knowledge of skills, and the competencies. It has specific goals of improving one's knowledge, skills and their capacity, capability, performance and their productivity. It is said that observers of labour market has clearly mentioned, more than initial qualifications for a work, to upgrade and update skills. Vigorous training and development should be three in the organization. Thus the training and development is the branch of human resource function. It is said that only training \& development is much important because it leads to an maximum utilization of all the some of firm. Thus the skills which were utilized by the human resource of firm can increase in output, quality improvement at the company. Training \& development increase in efficiency, increase of morale of employees, better human relatives, reduction in supervision, increased in organizational liability \& flexibility.

Training is said that both physically, socially, intellectually and rentally are very essential in facilitating the level of productivity, it also increase the development of personal in any organizations with that training is a systematic development of the knowledge, skills which is being required by employees to perform adequately on a given task or a job. Training can take place by number of ways, on the job on the job. Adult (1995) observed and said that staff training \& development is a work or an activity that makes an significant contribution to the overall effectiveness \& profitability to the organization. Training should provide a systematic approach to human being.

It clearly focuses on the importance and effectiveness of training and development which play a vital role in effectiveness of organization and university. To enhance the working atmosphere with the positive attitude. Ensuring the effectiveness of training session with the updated techniques in soft skills behavioral approach. To Update and check the overall development of the organization and the staff as well.

In summary, this importance and effectiveness of training and development is significant because it will be greatly impact the university. Moreover high quality performance is demanded by university; hence we should go with the rapid changes the terms of knowledge, technology and academic assignments. The objective of the training of effectiveness is important because it sheds lights on many aspects. However, unfortunately in today's organization, this mechanism of 
training evaluation should be taken into consideration. We have to continuously adopt to suit our current needs this is how possible our training leads to effective training.

Hence after identification of the important and effectiveness of training the next steps is to concentrate overall objective of the research paper is to fill the gap between existing training and get the important and effective of training at university.

Developing an effective employee training program is vital to the long-term success of the university. Training programs will be providing multiple benefits for employees and the company, but only if they are carefully planned and properly implemented. Clear understanding of policies, job functions, goals and company philosophy lead to increased motivation, morale and productivity for employees, and higher profits for university. Training is a means to a specific end, so keeping goals in mind during the development and implementation stages of your training program will assist in creating a clearly defined and effective program.

\section{Literatures Review}

Michel Armstrong has said that "Training is systematic development of the knowledge, skills and attitudes required by an individual to perform adequately a given task or job".

(Source: A Handbook of Human Resource Management Practice, Kogan Page, 8th Ed., 2001)

Edwin B Flippo has defined as, "Training is the act of increasing knowledge and skills of an employee for doing a particular job."

(Source: Personnel Management, McGraw Hill; 6th Edition, 1984)

The term 'training' Points the process involved in increasing the aptitudes, skills, Knowledge abilities of the employees to perform specific jobs. Training helps in updating old talents and developing new ones. 'Successful candidates placed on the jobs need training to perform their duties effectively'.

(Source: Aswathappa, K. Human resource and Personnel Management, New Delhi: Tata Mcgraw-Hill Publishing CompanyLimited,2000, p.189)

The principal objective of training is to make sure the availability of a skilled and willing workforce to the organization.

Casse and Banahan narrates that (2007), the different Viewed to training and development need to be explored. It has come to their attention by their own preferred model and through experience with large Organisations. The current traditional training continuously facing the challenges in the selection of the employees, in maintaining the uncertainty related to the purpose and in introducing new tactics for the environment of work and by recognizing this, they advising on all the problems, which reiterates the requirement for flexible approach.

Usually the managers have the choice to select the best training and development programme for their staff but they always have to bear in mind that to increase their chances of achieve the target they must follow the five points highlighted by Miller and Desmarais (2007)

Davenport (2006), mentioned in his study that it's easy to implement strategy with the internet supported software. Some of the Training theories can be effective immediately on the future of the skill and developments. The "content" and the "access" are the actual factors for the process. It is a representation itself by the Access on main aspect what is effective to the adopted practice in training development. As per the recent theories to access the knowledge is changing from substantial in the traditional to deliver the knowledge for the virtual forms to use the new meaning of information with electronic learning use. There is a survey confirmation for using classroom to deliver the training would drop dramatically, (Meister, 2001).

\subsection{Findings From The Interview}

Training is an effective investment necessary in any organization. There is need for technical training \& behavioral training among our staff members. These training make our employee feel confident and good. Many positive outcomes result among staffs after they attend training. These trainings are needed at every stage of professional life to enhance and update knowledge and widen the technical competencies. Training is successful when there is an involvement and interest among the staff members.

Training is essential for everyone, for successful completion of job. University is going beyond technology; hence training is very important for senior members who had joined earlier, well before the technology era. These senior members are willing to undergo training as they know that training is an effective investment. We can expect tangible results, an increase in human development, increase in commitment to the job, and increase in the morale of the 
employee. It also results in better understanding of human behavior. Training is necessary for an employee to improve the efficiency at work \& evolve in expending.

Training is more important in situations where an employee is introduced to a new system and expected to cop up with the changes that a new system introduces. Needs of the workplace are changing, work environment changes, which demands a balance between input and output. Recently our society is driven by technology and the employees at the workplace are also driven by technology. Hence, technical training at the workplace becomes very essential. Along with technical training, soft skill training is needed to perform well at the job. A Properly designed training program will definitely make the employees more productive.

Training is a continuous process that spans across the entire work period of the employees. When employees attend the training with dedication and carry with them the skills learnt and put into practice at their job, it produces excellent results

Training is absolutely necessary in every ones' profession, as it paves way to new platform. It lets the people to present their ideas in a very clear and simple way. It results in solid and permanent changes in an employee that enhances the efficiency.

Training is an integral part of employees in academic institutions that requires large investment. When this huge investment is properly planned and executed, it leads to a successful training program.

Training is a continuous process and it never stops at any phase of life. People should be willing to learn new things and update their knowledge frequently. Technology advancements are very fast and one needs to adapt to the change quickly. We cannot survive with what we had initially but need to keep in line with the demands of the society. Training brings a change in the mindset of the employee and also brings a positive attitude towards other workers and in the job

Training is very important for the successful functioning of an organization. For non teaching staff, computer training is very important. These people have to use the computer for almost all the work in their daily work. In-house training should be done in frequent intervals to keep these people updated and use the technology effectively

Training is a basic requirement in any field. One has to make use of this effective investment to make oneself the best. It makes the job easy, resources very user friendly, eases the workload and gives a healthy mind.

To current the attitude soft level process. Interest of learn / thirst may training success. Identify right people I effective person makes training success. Every employee needs to be trained but the type and the level of training may differ from one category to another category of workers. Training at university is successful for both faculty \& staff. Periodical follow-ups are done to monitor the progress so that training is done at the needed time.

Training in academic institutions help in producing good academic results. It keeps one updated. Technical training is good at the same. These training make the employees to have accelerated growth in their career. Trainers also are expert can be helpful. Yes some after training many skills language.

Due to training, computer soft skills have been improved drastically. Training is successful if it meets the needs of the employees. A good training program needs to get the feedback from the attendees so that the suggestions can be taken as the input for the next training program.

Training is mandatory for each \& everyone. It increases in the productivity of the individual and also the entire institution. Hence it is worth rewarding investment. Its fruitful results follow the days to come in future. As far the departments are concerned, everything now has become much automated. To keep oneself in the stream of automation, one has to use the training very effectively and benefit from it. Otherwise, we will be left behind soon to realize that everyone else has advanced very far. Training makes one very competent \& involvement of the employees makes the training successful.

Training is necessary to the institute. Yes training is an effective investment. Training makes us organization value and commitment. Training makes our organization to enable us in a process and fruitful way. Training good resource person, hence it makes training success.

Training is essential for everyone and is part of the career. Training should be customized to meet the needs of the employees.

\section{Methodology}

This is a pilot study based on the primary data collected from the Deans/Sec Heads in the University. Considering the nature of the present study, structured interview method was used in order to collect relevant information from a sample of 30 Deans/Sec Heads.. Rest of the potential respondents was either unavailable or not interested. Since the sample is 30 , content analysis was conducted from the data collected from the respondents. This methodology is chosen in order to 
bring out the clear response of the stake holders, members of the management, academicians, etc. When we collect the primary data based on the main concept what we take it efficiently leads us to go for better finding. Moreover the methodology is fruitful in giving a complete structure for the process which we under taken.

The biggest benefit of face to face interview is the human interactions that occurs the method was purposely selected so that the researcher would easily interact with the deans / directors/ section heads thus the interview are the one of the easiest tool for gathering information about the training importance and effectiveness

The desired outcome is to be found that the research will be a catalyst to proceed further the completion of paper would provide data that could be used as basis.

\subsection{Instrumentation}

The method chosen to collect data for the assessment is structure interview method specifically.

A face to face interview with directors/ dean/section heads

Structure interview method was followed by collect relevant information thus it allows effective decision making about the importance and effectiveness of training in a university. This was accomplished by the through a serious of meetings with the deans/directors/section heads.

Training objective in both quality and quantitative terms helps evaluating and monitoring the effectiveness of the training. It will give the best when objective of the training of the programme will be stated to them.

\section{Findings}

The objective of the study was to present the Importance \& Effectiveness of Training \& Development. The study adapted the interview method to find the solutions for the given Problem. Most of the questions relating to the Training \& Development were positively responded. Question relating whether Training can be effective investment, all the respondents answered positively. The question relating to the need for Behavioral/Technical training was extremely positive. One interesting finding in the study was that all the respondents have identified that there is a positive change in the staff after attended Training. The respondents interestingly Pointed out that the Training is essential for everyone \& to keep oneself in the stream of automation, staff should use the training very effectively. Training should be customized to meet the needs of the Dean/Sec Head. Training is a continuous process that spans across the entire work period of the employees. When employees attend the training with dedication and carry with them the skills learnt and put into practice at their job, it produces excellent results. The study finding on the accessibility of training \& development are Positive for all group of employees. Hence Training will meet the challenges at the work place and it will create a positive culture surrounding the human resource Management. University has a clear focus on having well motivated and trained people. The university staffs needs to have motivated skills in order to remain Competitive. In addition to the above points, well trained \& dedicative staffs are asset to any university.

\section{Conclusion}

The paper provides an insight of training and important / effectiveness of training. To make training more effectiveness organization requires to look at those training \& development is associated with the particular department managers should first motivate employees to learn acquire new skills \& knowledge. To conclude that training \& development programme conducted in the University was found to be good and the same may be said if it enhance its training development programme based on the above finding. Suggestion it would help employees. Different level of training is to be kept to different level of man power. Since employees in an organization will be able to perform their duties and can make meaningful contribution to the success to the organization goals. The study intends to carry the work further with larger number of respondents, may be with a wider frame. There is a document evident that training activities have a positive impact on the performance of the individuals and the teams. Training activities can also be beneficial other than the individual and the team level. Training will have the greatest impact when it is bundled with the organization objectives, Core Values etc. Many studies have gathered support the benefits of training for the university as a whole. While supporting the staffs and taking above all cases into consideration it is said that training and development creates a win situation for the employees and for university too. 


\section{References}

Acland, J. (1982) An Analysis of Development Training at Brathay Hall (unpublished research report) Brathay Hall Trust, Ambleside Allcock, R.S. (1988) Development Training: A Personal View, Endeavour Training, Birmingham

Beeby, J.M., and Rathborn, S. (1983) "Development Training - Using the Outdoors in Management Development" Management Education and Development 14 3, 170-181.

Bill C. and Greenaway R. (1989) The Competences of Development Trainers, The Training Agency, Manpower Services Commission ISBN 086392 300-3

Punia.Dr, "Factors affecting Training Effectiveness" (2013).Vol 2, IJARMSS

Kulkarni."Training \& Development" E-ISSN- 2013

Experience Based Training and Development (EBTD) (1998) Web page

Training and Development: Enhancing Communication and Leadership Skills, by Steven A. Beebe, Timothy P. Mottet and K. David Roach, 2012 